a case of inherited " acquired characters," was an exception to the other friends of the human race, and, indeed, was an enemy. But he made a remark of extreme importance to such a painfully pressing matter as' that before us, with which I will conclude. He says: "It is evident that in applying in practical matters the lessons that the biologists may teach us we must be certain that we are dealing with truths that will remain truths for this and for many generations." 1 I am, Sirs, yours faithfully,

Blackheath, May 6th, 1901.

WALTER KIDD.

\section{THE DEATHS FROM (?) BOXING.}

To the Editors of THE LANCET.

Sirs,-Surely the faculty ought to be able to help in throwing some sort of light on what appears to be a ghastly mystery in the matter of these last three deaths after boxing under apparently the safest of conditions-conditions nonexistent in other clubs where great numbers of severe contests take place. The mystery has hitherto been treated as a surgical affair, but I cannot help thinking there is a medical aspect to it which may be worth while considering, especially as the mystery remains unsolved by the surgicopathological theory. Admitting that intracranial hæmorrhage from a blow without fracture is " on the cards," I contend that, considering the millions of knocks, blows, and punches on the head which occur, it is most rare. In all these cases the boxing has been of such a high-class nature that no really violent blow was received on either side. In the first case, that of Turner, postmortem examination revealed no lesion whatever-the only peculiarity that could be spoken of was that the heart was smaller than the average. Yet be had won an open competition, meeting the picked men in England, only a week or two before. He was to be married the week after the contest at the National Sporting Club and alone supported a widowed mother. What could be have died from but nerve collapse due to overexcitement and anxiety? Yet public opinion put it down very naturally to boxing, pure and simple-killed by it. In the cases of Riley and Smith the necropsy showed intercranial hæmorrhage with no external marks of violence, much less fracture. Now I put it in this way : if this "case" last week had been brought into the hospital, not as one from the National Sporting Club, but one found insensible, sitting on a doorstep, of course the strictest search would be made for signs of outward violence; finding none, post-mortem examination shows intercranial bæmorrhage. How would death be certified-from "violence" or from " natural canses"?

Apoplexy may be uncommon in the young and apparently healthy, but I contend that nerve tension would be much more likely to cause it than any outward violence, though the surgical evidence was that the hæmorrhage could not have arisen without external concussion. I have witnessed practically every round of the amateur boxing championships for the last 21 years, where infinitely more severe punishment is given and taken than in these three cases. St. James's Hall is packed from floor to ceiling, any amount of shouting and chaff being indulged in by the spectators, the din being terrific at times, yet never has anything serious happened to the boxers. Can it be that the very strict rule of "silence during the boxing" at the National sporting Club has the effect of making the contest a much more intense mental strain to the competitor and conducing, therefore, towards nerve collapse and apoplexy? In all other clnbs spectators are allowed to cheer or otherwise during the boxing, thereby letting off the steam of excitement for onlookers and competitors. The officials of the club must indeed be almost driven crazy at finding their well-intentioned efforts to provide for the safety of the boxers end in such lamentable failure, and to sportsmen who take an interest in boxing these deaths have been very pathetic and heart-breaking. One does not get "nsed" to these kind of sad endings to contests fought out, as they almost always are, with the best of good feeling and even generosity.

I am, Sirs, yours faithfully, F. ORTON, M.D. Dub.

Crouch Fnd, Hornsey, N., May 6th, 1901.
“THE MEDICAL PROFESSION AND THE FRIENDLY SOCIETIES."

To the Editors of THM L $\mathbf{T}$ N OHT.

Sirs, - My attention has been drawn to the letter of “W. E. T." in THe LANCET of May 4th, p. 1301. Will you allow me to advise him and his neighbours not to undertake medical attendance under the terms and conditions offered by the National Friendly Society, if by this he means the National Deposit Friendly Society? The Medical Guild has twice discussed the claims of this society and has on both occasions declined to work on its terms.

I am, Sirs, yours faithfully,
Salford, May 7th, 1901.
R. HANSON WOLSTEN HOLME。

To the Editors of THE LANCET.

SIRS,- If the representatives of friendly societies and the General Medical Conncil will discuss their differences with the same spirit of fairness and anxiety for a definite settlement of the breach as is contained in Mr. Brabrook's letter, for which all medical men engaged in contract work will thank him, these constant disputes will soon be at an end. The wage-limit is a question upon which the friendly societies will never give in, and if the profession fight them on that question the result will be a further increase in the number of so-called "friendly societies medical institutions." The objects of these associations are laudable enough. It is often to be deplored that the friendly societies are under the impression that the medical profession attack the poor or working-classes who belong to these institutions; this is not so, the main cause for the dislike for these associations on the part of the profession is that they are largely composed of persons who can, and did formerly pay, a reasonable fee, and to fight against this we seem powerless. That the friendly societies do underpay their medical men can be proved over and over again. In Glasgow very recently a big lodge (A.O.F.) advertised for a medical man and offered $2 s$. $6 d$. per member per annum. He had to visit in a three-mile radius and find drugs, \&c. A registered friendly society the members of which are nearly, if not all, employed at a Government dockyard offered $2 s . \epsilon d$. per adult member and $\frac{1}{2} d$. a week for each child and wife of the members. Again, at a recent conference of Friendly Societies several prominent members openly confessed that they underpaid their surgeons. In my own district $I$ have to pay an assistant $£ 150$, indoors. My bill for drugs has considerably increased, the wages I pay have gone up-in short, my general expenses are much more than formerly. I have a colliery appointment and I put the question of a slight increase before the miners' committee and I met with refusal although I have been here since 1897 , when the colliers got $25 s$; in $1898,27 s .6 d$.; in $1899,29 s .4 d$. ; in $1900,33 s 4 d$. ; and in $1901,34 s$. Wages have gone up generally, the working man's position has improved, and he can well afford to pay a fair sum for contract work. What is that sum?

I contend the majority of us would be satisfied with $4 s$. per annum for juveniles, 4s. per annum for adult male, and $5 s$. per annum for female, members. I have a club with 250 adult members who pay me $4 s$. per annum for each member, a sum I am satisfied to atitend them for. They have established a juvenile club of 150 members, little boys and girls. They insist on my taking them at one halfpenny per member-6s. $3 d$. a week. This would mean about 4 per cent. on my list always. I pointed out that I would get nothing out of it, whereupon they threatened to withdraw the adult lodge or to join other societies in the establishment of an institution. 'It is in cases such as the one just cited where the friendly society members deal harshly with the doctor, in fact, any attempt on our part to combine with a view to remedy these grievances is looked upon by the trades union working man oddfellow as extremely aggressive. We only want what is fair and I hope Mr. Brabrook will use his influence with friendly societies towards that end.

May 6th, 1901. I am, Sirs, yours faithfully,

Water in Butrer.--At the Bristol Policecourt on April 30th a firm of butter manufacturers of Wellington, Somerset, were fined £21 for selling three samples of butter containing $28.3,26.2$, and 23.3 per cent of water respectively. 